\title{
Short Term Versus Long Term Catheterization after Urogenital Prolapse Surgery
}

\author{
Choudhury FR ${ }^{1}$, Rashid $\mathrm{M}^{2}$, Rumana $\mathrm{R}^{3}$, Uddin $\mathrm{ABMZ}^{4}$, Ava NN ${ }^{5}$
}

\begin{abstract}
Background: Genital prolapse is a common gynaecological problem in developing country like Bangladesh. Objectives: The aim of this study was to evaluate the advantages of short term catheterization in comparison to long term catheterization after genital prolapse surgery. Methodology: This was a prospective analytical cross sectional study being carried out from 1st July 2005 to 30th July 2006 in the Department of Gynaecology \& Obstetrics of Sir Salimullah Medical College \& Mitford Hospital. A total of 200 patients undergoing genital prolapse surgery were selected for this study. Patients were divided into two groups. In short term catheterization group the urinary catheter was withdrawal within one day after surgery and in the short term catheterization group the catheter was remained in situ for 5 days after surgery. Result: Positive urine culture was found in $16 \%$ in long term catheterization group compared with $6 \%$ in short term group $(\mathrm{P}=0.02)$. Mean duration of hospital stay was 6.98 days in long term catheterization group and 4.68 days in short term catheterization group $(\mathrm{P}<0.01)$. Residual volume was more than $200 \mathrm{ml}$ and need for re-catheterization occurred in $3 \%$ in group whereas it was $10 \%$ in case group $(\mathrm{P}=0.04)$. Conclusion: This study permits to conclude that short term catheterization is better than long term catheterization.
\end{abstract}

Key words: Genital prolapse, short term catheterization, long term catheterization

\section{Introduction}

Genital prolapse is a common condition met in day to day gynae practice ${ }^{1}$. Defects in the pelvic supporting structures result in a variety of clinically evident pelvic relaxation abnormalities. Most of the surgical treatments for prolapse aim to lift the prolapsed organ back into place ${ }^{2}$. Vaginal hysterectomy is the only treatment that removes the prolapsed organ altogether. Catheterization for five days after prolapse surgery is an accepted practice ${ }^{3}$. As, in uncomplicated prolapse surgery there is not too much interference in nerve supply of bladder \& urethra, removal of catheter in first post operative day, should not effect natural urination. It encourages patients rising from bed as soon as possible, reduces post operative chest, bladder \& alimentary tract complications, avoiding muscle wasting and ensures rapid physical and mental recovery from operation and rapid turn over of patients in hospital.

\section{Methodology}

Patients were divided into two groups. After taking history, general examination and local examination and after proper pre-operative check-up, the patients underwent surgery. One hundred patients were allocated for short term catheterization. On the first POD, after removal of catheter, when patient felt urge for voiding, patient was sent to USG
Dept. to measure residual urine volume and urine was sent for routine \& microscopic examination \& culture sensitivity and was advised to void frequently in order to prevent retention. If the urine examination was normal, the patient was discharged from hospital on third POD. The patients with imminent overfilling, (i.e. Post-voiding residual $200 \mathrm{ml}$ ) were re-catheterized for about another 3 days. One hundred patients were allocated to standard prolonged catheterization (catheter removal on the morning of 5th POD). After removal of catheter on 5 th $\mathrm{POD}$, urine was sent for routine examination and USG was done to measure residual urine volume. If the urine examination report was normal, the patient was discharged on 6th POD. Duration of hospital stay for both groups patients were recorded (Considering the patients were admitted before the day of operation). After operation initial follow up was given to anticipate evidence of infection and ensured about evacuation of bladder. Ethical clearance was taken from concerned local committee. Data is analyzed by Statistical Package Social Science, version 17.

\section{Results}

A total number of 200 patients were enrolled in this study of which 100 patients were selected as short term catheterization group and the rest 100 patients were selected as long term catheterization group.

1. Dr. Farzana Rabee Choudhury, Junior Consultant, Department of Gynecology \& Obstetrics, Shaheed Suhrawardy Medical College, Dhaka

2. Prof. Dr. Maliha Rashid, Academic Director, Central Hospital, Dhaka

3. Dr. Ratu Rumana, Associate Professor, Department of Gynecology \& Obstetrics, Sir Salimullah Medical College, Dhaka

4. Dr. ABM Zakir Uddin, Junior Consultant (Orthopaedics), Srenagar, Munshigonj

5. Dr. Nilufar Nasrin Ava, Assistant Professor, Department of Gynecology \& Obstetrics, Sir Salimullah Medical College, Dhaka

\section{Correspondence}

Dr. Farzana Rabee Choudhury, Junior Consultant, Department of Gynecology \& Obstetrics, Shaheed Suhrawardy Medical College, Dhaka; Email : drrabin_1971@yahoo.com; Mobile : 01556647890 
Table 1: Distribution of mean age among the study population $(\mathbf{n}=\mathbf{2 0 0})$

\begin{tabular}{ll}
\hline Mean Age of study groups & Mean \pm SD \\
\hline Short term catheterization & $50.40 \pm 7.62$ \\
Long term catheterization & $50.78 \pm 5.68$ \\
\hline
\end{tabular}

The mean age $\pm \mathrm{SD}$ of short term group was $50.40 \pm 7.62$ years and long term group was $50.8 \pm 5.68$ years (Table 1 ). Mean age of both groups was almost similar.

Table 2: Rate of Re-catheterization in both groups of study patients $(n=200)$

\begin{tabular}{lccc}
\hline \multirow{2}{*}{ Recatheterization } & \multicolumn{2}{c}{ Catheterization Group } & \multirow{2}{*}{ P value } \\
\cline { 2 - 3 } & $\begin{array}{c}\text { Short term } \\
(\mathbf{n}=\mathbf{1 0 0})\end{array}$ & $\begin{array}{c}\text { Long term } \\
\mathbf{( n = 1 0 0 )}\end{array}$ & \\
\hline Yes & $10(10.0 \%)$ & $03(3.0 \%)$ & \\
No & $90(90.0 \%)$ & $97(97.0 \%)$ & 0.04 \\
Total & $\mathbf{1 0 0 ( \mathbf { 1 0 0 . 0 } \% )}$ & $\mathbf{1 0 0}(\mathbf{1 0 0 . 0} \%)$ & \\
\hline
\end{tabular}

Re-catheterization was needed in $3.0 \%$ in standard prolonged catheterization group versus $10 \%$ in short term catheterization group $(\mathrm{P}=0.04)$ and the re-catheterization was done when the residual volume of urine exceeded $200 \mathrm{ml}$ (Table 2).

Table 3: Urinary tract infection in both groups of patients $(n=200)$.

\begin{tabular}{lccc}
\hline \begin{tabular}{l} 
Urinary tract $\begin{array}{l}\text { Catheterization Group } \\
\text { infection }\end{array}$ \\
\cline { 2 - 3 }
\end{tabular} & $\begin{array}{c}\text { Short term } \\
(\mathbf{n}=\mathbf{1 0 0})\end{array}$ & $\begin{array}{c}\text { Long term } \\
(\mathbf{n}=\mathbf{1 0 0})\end{array}$ & \\
\hline Present & $6(6.0 \%)$ & $16(16.0 \%)$ & \\
Absent & $94(94.0 \%)$ & $84(84.0 \%)$ & 0.02 \\
Total & $\mathbf{1 0 0}$ & $\mathbf{1 0 0}(\mathbf{1 0 0 . 0} \%)$ & \\
\hline
\end{tabular}

Chi-Square Tests $=5.107, \mathrm{df}=1, \mathrm{p}=0.02,($ Significant $)$

The positive urine culture were found in $16.0 \%$ of cases in standard prolonged catheterization group compared with $6.0 \%$ in short term catheterization

Table 4: Shows mean and \pm SD of hospital stay in both groups $(\mathbf{n}=\mathbf{2 0 0})$ :

\begin{tabular}{llll}
\hline Study groups & Mean & \pm SD & P value \\
\hline $\begin{array}{l}\text { Short term } \\
\text { catheterization }\end{array}$ & 04.68 & \pm 1.07 & \\
$\begin{array}{l}\text { Long term } \\
\text { catheterization }\end{array}$ & 06.98 & \pm 0.84 & $<0.01$ \\
\hline
\end{tabular}

Mean duration of hospital stay was 06.98 days in standard prolonged catheterization group and 04.68 days in the short term catheterization group $(\mathrm{p}<0.01)$.

\section{Discussion}

The use of urinary catheter after genitourinary surgery is accepted practice to enable drainage and prevent over distension of bladder ${ }^{1}$. The most common problem of post operative infection is associated with indwelling catheter drainage $^{2}$. The present series concerns with the short term versus long term catheterization after genital prolapse surgery of 200 cases. One Study by Hakvoot et $\mathrm{al}^{1}$ was done to determine whether prolonged urinary bladder catheterization after vaginal prolapse surgery is advantageous ${ }^{1}$. Design was randomized controlled trial in a large training hospital in Netherland. Population was patients undergoing only anterior colporrhaphy. One hundred patients were included. Patients were randomized into two groups. In one group $(\mathrm{n}=50)$, a transurethral catheter was in place for four days post-operatively and removed on the fifth post-operative day. In the other group $(n=50)$, catheterization was not prolonged and the catheter was removed on the morning after surgery. Residual volumes after removal of the catheter were measured by ultrasound scanning. When residual volumes of $>200 \mathrm{ml}$ were found the patient was re-catheterized for three more days .Urinary cultures were taken before removal of the catheter again. Main outcome measures were need for recatheterization, urinary tract infection, mean duration of catheterization and hospital stay. Results was residual volumes exceeding $200 \mathrm{ml}$ and need for re-catheterization occurred in $9 \%$ in the standard prolonged catheterization group versus $40 \%$ of patients in the not prolonged group . But population of the study was patients undergoing different types of prolapse surgery \& found that need for recatheterization is 3\% in standard prolonged catheterization group and $10 \%$ patients in not prolonged group $(\mathrm{P}=0.04)$. In another prospective randomized controlled trial by Dunn et $\mathrm{al}^{4}, 250$ women underwent hysterectomy and the indwelling catheter was removed either immediately or on the first day after operation. Need for re-catheterization was in 3 patients in indwelling catheter group compared with 5 patients in the early removal group. So catheter removal just after operation needs more re-catheterization rate. But indwelling catheter has been associated with increased bacterial counts and catheterization causes bacteruria to account at a rate of $3-10 \%$ patients per day ${ }^{3}$. In Hakvoort ${ }^{1}$ study positive urine culture was found in $40 \%$ cases in the not prolonged group. This study showed that $16 \%$ of prolonged catheterization group was compared with $6 \%$ in short term group and had positive urine culture $(\mathrm{P}=0.02)$. Another study suggested symptomatic urinary tract infections in 3 patients in both groups of indwelling on the first day after operation ${ }^{4}$. Summit et $\mathrm{at}^{5}$ had a study on 100 women undergoing routine vaginal hysterectomy, randomly assigned to have an indwelling Foley's catheter for 24 hours following surgery. At 48 hours the incidence of positive urine culture was $48 \%$ in the indwelling catheter group which was too large number in comparison to the present study. The risk of catheter related UTI increases with the length of time of catheterization. Bacteria generally present after 72 hours 
and increase of catheter related UTI is approximately $8 \%$ per day ${ }^{6}$. The best prevention for catheter related UTIs is catheter removal as soon as possible. Use of an indwelling catheter after gynecological surgery has been shown to a affect the length of hospitalization ${ }^{5}$. Mean duration of catheterization was 5.3 days in long term catheterization group and 2.3 days in short term group in Hakvoort ${ }^{1}$ study $(\mathrm{P}<0.001)$. And mean duration of hospitalization was 7 days in prolonged catheterization group and 5.7 days in short term group ${ }^{1}$. The present study showed mean duration of hospitalization 6.78 days in standard prolonged catheterization group and 4.68 days in short term catheterization group $(\mathrm{P}<0.01)$. Another Study done by Glazener ${ }^{7}$ gave similar result. Recatheterization with an indwelling catheter is also debatable. Now a day's intermittent catheterization may be more appropriate because of the reduced risk of UTI and establishment of a more natural filling and emptying cycle ${ }^{1}$.

\section{Conclusion}

Indwelling catheter use after major uncomplicated gynaecological surgery has been the standard method of practice of bladder treatment after the operation. Therefore gynaecologists have justified the routine use of indwelling urinary catheter. Disadvantages of long term catheterization after vaginal prolapse surgery clearly outweigh the advantages. Shorter duration of catheterization is preferable as it results in low incidence of UTI, potential cost savings, less patient discomfort and early patient ambulation. Long term catheterization is to be undertaken in specific cases and surgeons should have working experience to predict when it is indicated. Routive use of indwelling catheterization should be avoided after simple hysterectomy.

\section{References}

1. Hakvoort RA, E lberink R, Vollebregt A et al. How long urinary bladder catheterization should be continued after vaginal prolapse surgery? A randomized controlled trial comparing short term versus long term catheterization after vaginal prolapse surgery. BJOG 2004; 111:828-832

2. Givens CD, Wenzel Rp. Catheter Asssaiated Vrinary tract infections in surgical patients: a controlled study on the excess morlridity. J Urd 1980; 124: 646-8.

3. Woods Dr, Bender BS. Long term wrinary tract eatheterization. Med Clin North Am. 1989;73(6): 1441-54.

4. Dunm TS, Judiths, Dave F. Are indwelling catheters necessary for 24 hours after hysterectomy? Am J obstet Gynecol 2003;189:435-7.

5. Summitt RL, Stovall TG, Bran DF. Prospective comparison of indwelling bladder catheter drainage versus no catheter after vaginal hysterectomy. AM J Obstet Gynecol 1994:70:1815-9.

6. Garibaldi RA, Burke JP et al. Bacteruria during indwelling catheterization. J Infect control 1988; 11 (3): 253- 2625

7. Glazener CMA, Cooper K. Anterior vaginal repair for urinary incontinence in women (Cochrane Review). In: The Cochrane Library, Issue 1. Oxford: Update Software; 2001

8. Thompson JD. Hysterectomy. In: Thompson JD, Rock JA, editors, Lelindis operative Gynaecology 7th ed. Philadelphia: Lippincott; 1992, pp.663-738.

9. Martinez Dv, Civette JM, Anderson Ketall. Bacteriuria in the catheterized surgical case patient. Criti Care Med 1986;3:188-91

10. Richardson AC, Lyon JB, Graham EE, et al. Abdominal hysterectomyrelationship between morbidity and surgical technic. Am J obstet Gynecol 1973;116:953-61 